\title{
NOVAS ABORDAGENS NO ENSINO DE ENFERMAGEM FUNDAMENTAL: EXPERIEENCIA DOCENTE NO ENSINO DA ÉTICA PROFISSIONAL
}

\author{
Therezinha Teixeira Vieira ${ }^{1}$ e Darci Santa Rosa de Oliva ${ }^{2}$
}

RESUMO. O trabalho apresenta alguns dados históricos do ensino da ética na Escola de Enfermagem da UFBA e situa a disciplina Exercício de Enfermagem e Deontologia no Currículo atual desta Escola. São explicitados o marco conceitual, os objetivos, o conteúdo programático, as estratégias utilizadas e o processo de avaliação. Após as conclusões, são feitas recomendações consideradas adequadas ao assunto.

ABSTRACT. Some historical data of Ethics teaching in the Nursing School of the Federal University of Bahia are presented in this work. Moreover, the nursing exercise and deontology discipline in actual curriculum this school are located. The conceptual starting point, the objectives, the program content, the strategies that are utilized and the evaluation process are explicited. After the conclusions some recomendations considering adequated to the subject were made.

\section{INTRODUÇĀO}

É objetivo deste trabalho apresentar o relato de nossa vivência no ensino do Exercício de Enfermagem e Deontologia, para alunos do curso de graduação da Escola de Enfermagem da Universidade Federal da Bahia.

Esta experiência vem sendo desenvolvida, desde o segundo semestre de 1981.

\section{ENSINO DA ÉTICA PROFISSIONAL NA ESCOLA DE ENFERMAGEM DA UNIVERSIDADE FEDERAL DA BAHIA}

- Alguns dados históricos

O primeiro currículo desta Escola, iniciado em março de 1947, foi estruturado sob a forma de listagem de disciplinas a serem desenvolvidas durante um período de quatro anos. Assim, registra-se a disciplina Ética, não constando, porém, na fonte de dados, a carga horária específica e o conteúdo programático.

Em 1953, surgem programas de Ética, para os 30 e 4 o anos do curso, com assuntos que englobam ética geral e profissional. mas sem que sejam especificadas a carga horária e a dinâmica de desenvolvimento.

Com as reformulações processadas no currículo a partir de 1960, surge então, a disciplina Ética e Ajustamento Profissional, com uma carga de 20 horas.

De 1966 a 1968, a disciplina é ministrada no 10 e 3 o ano, sob o nome de Ética e História da

1 Professor Titular da Escola de Enfermagem da Universidade Federal da Bahia. •

2 Professor Assistente da Escola de Enfermagem da Universidade Federal da Bahia. 
Enfermagem, apresentando objetivos especificos, mas sem uma definição de conteúdo programático.

Com as exigências da reforma universitária, sofreu o currículo novas reformulações e o ensino da ética foi desdobrado em dois tempos: 1) Ética I com 45 horas, onde são abordados seus aspectos básicos e gerais, já agora sob a responsabilidade do Departamento de Filosofia da Faculdade de Filosofia e Ciências Humanas. Esta modificação ocorreu com a finalidade de obedecer à filosofía da Reforma Universitária, e 2) Problemática de Enfermagem, também com um total de 45 horas, insuficientes para o conteúdo abrangente de História da Enfermagem, Exercício Profissional e Ética Profissional.

Em 1980, realiza-se a última modificação no Currículo da Escola e a disciplina Problemática de Enfermagem deu lugar à nova disciplina Exercício de Enfermagem e Deontologia, que passou a ser ministrada a partir do segundo semestre de 1981 .

\section{DISCIPLINA - EXERCICIO DE ENFERMAGEM E DEONTOLOGIA}

\section{- Situação da disciplina no Currículo}

Compondo a matéria Exercício de Enfermagem, a disciplina Exercício de Enfermagem e Deontologia possui uma carga horária de 45 horas, correspondendo a três créditos, sendo oferecido no 70 semestre. Tem como pré-requisito a Ética I (V. Anexo I), disciplina complementar obrigatória, com a mesma carga horária e creditação da anterior e prevista para o 30 semestre, como indica o fluxograma do curso.

\section{- Marco conceitual}

A disciplina tem como marco conceitual o ser humano (cliente e profissional) inserido em uma sociedade e, mais especıficamente, na sociedade brasileira.

A aprendizagem verifica-se pela condição do aluno através de um processo reflexivo, que leve a encerar o exercicio profissional da enfermagem e seus aspectos éticos, dentro de uma visão histórica. Procura objetivar o desenvolvimento intelectual do estudante, em direçāo a uma atitude profissional crítica e criativa.

\section{- Objetivos}

Ao finalizar o curso o aluno deve ser capaz de:
- distinguir os princípios éticos e morais que devem reger a conduta na vida pessoal e profissional;

- identificar a importância de uma escala de valores como norma de vida e avaliar a observância da mesma em sua própria vida;

- identificar os valores da profissão e sua relação com o contex to da sociedade brasileira:

- discorrer sobre a legislação. especifica da enfermagem;

- anạlisar o Código de Deontologia em Enfermagem nos seus diversos aspectos;

- estar informando sobre os objetivos e características do Conselho de Enfermagem a nivel Federal e Regional.

\section{- Conteúdo programático}

O conteúdo programático é desenvolvido considerando-se duas unidades.

A primeira unidade é iniciada com uma revisão sobre o sentido do ser humano, inserido na sociedade, enfatizando-se a temática dos valores. Discute-se o assunto, levando a classe a identificar os valores que regem a nossa sociedade, seus desvios decorrentes da estrutura sócio-política e sua relação com os valores da profissão.

Estuda-se, a seguir o caráter histórico da moral, ou seja, como as mudanças histórico-sociais influenciam as mudanças morais. Reflexões são feitas em torno de problemas morais e éticos.

A conceituação de direito e dever é discutida, passando-se a uma análise crítica da Carta dos Direitos Universais do Homem.

Esta unidade termina com um estudo sobre o sentido da Lei, sua conceituação e distinção entre lei jurídica e moral, situando-se a Constituiçāo Brasileira como base das demais leis.

Com esse referencial teórico estudado, passa-se à segunda unidade do programa. mais voltada para os aspectos específicos da profissão. Ela é desenvolvida a partir da legislaçāo profissional, procurando-se situar seus objetivos e as principais leis que regem a enfermagem brasileira.

O Código de Deontologia em Enfermagem é analisado, considerando-se suas diversas partes. A partir, de então, temas específicos são estudados como, por exemplo, exercício profissional frente aos valores do paciente/cliente, abortamento, planejamento familiar, sigilo profissional e morte, realçando-se aqui o aspecto da eutanásia.

No que se refere ao enfermeiro perante a clas- 
se e a sociedade, um estudo das Associações de Classe é desenvolvido, distinguindo-se. a partir de suas finalidades, Associação, Sindicato e Conselhos, procurando situá-las como instrumentos de crescimento da classe profissional, em sua dinâmica interna e externa, e em sua relação com a sociedade. O Conselho é realçado como órgão normativo e disciplinador do exercício profissional abordando-se especificamente os códigos de processo ético de infrações e penalidades.

O conteúdo programático é finalizado com uma exposição sobre o ethos da atividade científica de enfermagem ( V. Anexo).

\section{- Dinàmica do desenvolvimento do Curso}

Inicialmente o programa é apresentado aos alunos, com a discussão de seus objetivos, estratégias e instrumentos de avaliação.

Um pré-teste é aplicado, constando dos aspectos éticos básicos, pré-requisitos para o desenvolvimento do curso.

As aulas são ministradas em três horas semanais, sendo enfatizada a reflexão sobre os conteúdos apresentados.

Utiliza-se, primordialmente, a técnica de dinâmica de grupo, com formação espontânea de pequenos grupos de trabalho, onde se processam análises e discussões sobre assuntos escolhidos. Os resultados são apresentados no grupo maior, onde a discussão é ampliada, havendo correções, se necessário, e ocorrendo, sistematicamente, uma complementação pelos professores.

Com essa dinâmica proporciona-se a o aluno a leitura e discussão de textos selecionados. Situações-problemas, vivenciadas pelos estudantes em estágio ou levantadas pelos professores, são trazidas para análise, de acordo com o referencial teórico estudado em classe.

O estudo do Código de Deontologia é feito, considerando-se cada uma das partes que o compõem. Temas específicos e explicitados no Código são estudados através de Seminários, deixando-se a critério dos grupos, a escolha da técnica de apresentação, que tem como norma a orientação para a discussão reflexiva.

O aluno tem plena liberdade para levantar dúvidas e questionamentos os quais são debatidos entre eles próprios e os professores. Elementos da comunidade são convidados por professor e/ou alunos para participarem de discussões de assuntos especificos.
Para a aparesentação dos trabalhos, é oferecido ao aluno um guia de orientação. além da oportunidade de discutir com os professores seus esquemas e a escolha de bibliografia.

\section{- Avaliação}

A avaliação é iniciada com a aplicação do pré-teste e, subseqüentemente, através de:

- Exercício de aplicação, centrado, sobretudo, em situaçōes-problemas relacionadas à vivência do profissional com o cliente e seus familiares, com a equipe de saúde e as instituições em que trabalham, tomando por base o referencial teórico estudado.

- Apresentação e discussão de temas por diversos grupos, onde se considera: conteúdo, capacidade de associar a teoria à prática, estímulo da classe à reflexão, participação de cada componente do grupo e a técnica de apresentação.

- Elaboração de trabalho escrito sobre tema discutido em classe.

- Auto-avaliação, realizada pelos estudantes que apresentam os trabalhos, incluindo a emissão de conceitos, ao tempo em que se pede aos demais componentes da classe que também avaliem os colegas apresentadores.

- Participação do aluno no desenvolvimento do curso, considerando-se:

freqüência às aulas, participação nas discussões, desde as simples solicitações de esclarecimentos até questionamentos levantados e às contribuições nas resoluções de situações problemas.

\section{- Avaliação do Curso pelos alunos}

A avaliação do curso é efetuada pelos estudantes no último dia de aula, através de duas técnicas: a) uma dinâmica de grupo, onde se oferece oportunidade aos alunos para que se expressem, informando oralmente como se sentiram no desenvolvimento do curso, relacionando o seu pronunciamento ao referencial teórico estudado; b) questionário, onde o aluno não precisa identificar-se, mas deve expressar, individualmente, sua opinião sobre conteúdo, estratégias, avaliação, relação professor-aluno e, fornecendo sugestões para possiveis mudanças.

A avaliação é somativa, além de formativa, desde quando a meta da disciplina é a formação de atitude direcionada a uma prática profissional consciente, crítica e criativa. 


\section{FACILIDADES}

- Programa da disciplina elaborado pela professora, responsável pelo ensino da mesma desde o seu início.

- Participação de mais uma professora, a partir do 29 semestre de sua implementação e que passou a comungar da mesma filosofia de sua dinâmica.

- Aceitação e interesse por parte dos alunos, principalmente a partir da 3 ạ semana de aula e boa-vontade em avaliar a disciplina.

- Colaboração de professoras de outras disciplinas e de colegas que atuam nas Associações de Classe.

\section{DIFICULDADES}

- Deficiência do pré-requisito, ou seja, o curso da disciplina Ética I não está correspondendo às expectativas dos estudantes e da própria disciplina Exercício de Enfermagem e .Deontologia.

- Carga horária reduzida.

- Aulas com duração de três horas seguidas, ministradas em apenas um dia da semana.

- Suficiência bibliográfica.

- Dificuldade dos alunos em acompanhar uma dinâmica de trabalho, com base em reflexão.

- Professores não preparados especificamente, para a referida disciplina.

\section{CONCLUSÕES}

A experiência do ensino da disciplina Exercício de Enfermagem e Deontologia vem sendo positiva, a medida que sentimos e verificamos o crescimento, tanto de professores, como de alunos, considerando-se os resultados das avaliações que vêm sendo efetuadas.

No entanto, constata-se que muito, ainda, tem de ser realizado, não só quanto à formação do professor, mas no que se refere à carga horária da disciplina, seus conteúdos e estratégias a serem desenvolvidas desde os pré-requisitos.

Conclui-se, também, que o conteúdo dessa disciplina só será absorvido com mais intensidade pelos alunos, quando for incluído nas disciplinas profissionalizantes, o que exigirá, naturalmente, uma integração maior com os demais professores da Escola.

\section{RECOMENDAÇÕES}

Recomenda-se que:

a) na formação do enfermeiro, haja um estudo mais aprofundado dos aspectos ético-morais;

b) o ensino da Deontologia de Enfermagem, seja precedido pelo estudo da Ética Geral nos seus aspectos básicos;

c) o ensino da Ética Profissional seja ministrado dentro de uma visão sócio-histórica, procurando-se identificar os valores da profissão e sua relação com o contexto de sociedade em gerdl e, em específico, da sociedade brasileira;

d) seja dada oportunidade ao aluno de analisar criticamente o Código de Deontologia;

e) sejam utilizadas as estratégias de situações-problemas vivenciadas pelos próprios estudantes, em seus campos de estágio, para análise dos problemas éticos e morais, tomando por base o Código de Deontologia e os aspectos básicos da moral humana;

f) os temas da ética, além de ser discutidos na disciplina específica, sejam integrados em todas as disciplinas profissionalizantes;

g) seja estudado qual o semestre do curso mais adequado para se ministrar as disciplinas que correspondem à Ética Geral em seus aspectos básicos e à Ética Profissional;

h) ao lado dos outros aspectos fundamentais da Ética Profissional, no ensino da Deontologia em Enfermágem procure-se explicitar, com clareza, o papel do Conselho de Enfermagem como órgāo normativo e disciplinador do exercício profissional.

VIEIRA, T.T. \& OLIVA, D.S.R. New approach in the fundamental nursing: teacher experience in the protissional ethics teaching. Rev. Bras. Enf.. Brasília, 38 (2):

| 191-194. abr./jun. 1985.

\section{REFERÊNCIAS BIBLIOGRÁFICAS}

1. CONSELHO FEDERAL DE ENFERMAGEM. Códigos de deontologia de enficrmagem, processo ético, transgressōes e penalidades. Brasilia. 1978.

2. - Documentos básicos do COFEN. Rio de Janeiro. 1983.

3. COORDENADORIA ECUMENICA DE SERVIÇO. Declaração Universal dos Direitos Humanos. Salvador, 1981.

4. GELAIN, Y. Deontologia e enfermagem. São Paulo. EPV, 1983.

5. VÁSQUEZ, A.S. Ética 2. ed. Rio de Janeiro, Civilização Brasileira, 1975. 
6. VIEIRA, T.T. et alii. Evolução história do currículo da Escola de Enfermagem da Universidade Federal da Bahia. Rev. Baiana de Enf., Salvador, 1 (1): $73-89,1983$.

Obs.: Além da bibliografia citada, foram consultados o
Plano de Curso e o Programa de disciplinas ministradas na Escola de Enfermagem da UFBa, de 1942 a 1984 - Etica, Ética e História da Enfermagem, Ajuntamento profissional (conteúdo de Ética), Problemática da Enfermagem e Exercício de Enfermagem e Deontologia. 


\section{ANEXO I}

UNIVERSIDADE FEDERAL DA BAHIA

ESCOLA DE ENFERMAGEM

DEPTỌ DE ENFERMAGEM MÉDICO CIRÚRGICA E ADM. DE ENFERMAGEM

DISCIPLINA: EXERCICIO DE ENFERMAGEM E DEONTOLOGIA

\section{CONTEÚDO PROGRAMÁTICO}

UNIDADE I -A ENFERMAGEM, A ÉTICA, A MORAL E A LEI JURIDICA NUM CONTEXTO SÓCIO-HISTÓRICO:

$$
\begin{aligned}
1 \text { - } & \text { MORAL E HISTÓRIA } \\
& - \text { Caráter Histórico da Moral } \\
& - \text { Mudanças Histórico-Sociais e Mudanças Morais } \\
2 \text { - } & \text { PROBLEMAS ÉTICOS E MORAIS } \\
3 \text { - } & \text { A ENFERMAGEM E OS DIREITOS HUMANOS } \\
& - \text { Direitos e Deveres na Vida Humana } \\
& - \text { Direitos Universais do Homem } \\
4 \text { - A ENFERMAGEM E A LEI JURIÓICA E MORAL } & \text { Carga Horária: } 09 \text { horas }
\end{aligned}
$$

UNIDADE II - DEONTOLOGIA EM ENFERMAGEM E EXERCICIO PROFISSIONAL:

$$
\begin{aligned}
1 \text { - LEGISLAÇÃO DA ATIVIDADE PROFISSIONAL EM ENFERMAGEM } \\
\text { - Objetivos } \\
\text { - Principais Leis }
\end{aligned}
$$$$
2 \text { - CÓDIGOS NORMATIVOS DA PROFISSÃO }
$$$$
2.1 \text { - Código de Deontologia em Enfermagem }
$$$$
\text { - Aspectos Jurídicos e Morais }
$$$$
\text { - Conteúdo: }
$$

- Responsabilidades Fundamentais do Enfermeiro

- Exercício Profissional

. Enfermeiro perante a Classe

- Enfermeiro perante os Colegas e demais Membros da Equipe de Saúde

. O Enfermeiro e Sociedade

2.2 - Código de Processo Ético

2.3 - Código de Infrações e Penalidades

3 - O ethos da atividade científica de enfermagem

Carga Horária: 36 horas 